\title{
Epidemiology of urinary tract infection in south India
}

\author{
Christy VR ${ }^{1}$, Athinarayanan $\mathrm{G}^{2}$, Mariselvam $\mathrm{R}^{3}$, Dhasarathan $\mathrm{P}^{4}$ and Singh RAJA** \\ ${ }^{1}$ Vivek Laboratory and Research Centre, Nagercoil, India \\ ${ }^{2}$ Department of Microbiology, SRNY College, Tenkasi, India \\ ${ }^{3}$ Centre for Biotechnology, St. Xaviers College, Palayamkottai, India \\ ${ }^{4}$ Department of Biotechnology, Prathyusha Engineering College, Chennai, India
}

\begin{abstract}
Urinary tract infection is one of the infectious diseases affecting both genders. The causative microbial pathogens invade the urinary tract tissues extending from the renal cortex to the urethral meatus. The prevalence of drug resistant microbes in urinary tract infected cases is a major problem to solve. With this background the epidemiology of urinary tract infection among the population of Kanyakumari District, South India was studied. For the present study medical practitioners suspected cases visiting for clinical evaluation in a major clinical laboratory were chosen as samples. In a period of 6 months observation a total of 1824 cases were subjected to various clinical analysis. Among them 1029 were females and 795 were males. A clinical examination of the suspected cases showed culture positive in the samples taken from males (37.23\%) and females (37.99\%). The age wise study of the culture positive cases indicates that the UTI infection occurs from infants (1 month) to elderly people (90-100 years). In the study area the percentage of UTI is common in women in the reproductive age and post-menopausal stage. Diabetic mellitus prevalent in post-menopausal women has a link with UTI incidence. In the elderly aged male's diabetes and prostrate problem enhances UTI. The pregnant women and newly married women in the age group 21-30 are more prone to UTI. The present study also reports pediatric UTI in both genders. Lifestyle changes, poor personal hygiene, nutritive problem, catheter use, unclean baby napkins and immune deficiency were identified to be the factors favoring UTI in the study area. An analysis of UTI positive culture showed the presence of Escherichia coli, Klebsiella pneumoniae, Staphyllococcus saprophyticus, Margonella margonii, Streptococcus sp, Staphyllococcus aureus, Enterococcus sp, Proteus vulgaris, Chromobacterium violaceum, Serratia spp and the fungi Candida sp.
\end{abstract}

\section{Introduction}

Urinary tract infection (UTI) is a contagion among men and women but the incidence is found high among women due to their biological conditions [1]. In the urino-genital system, the output from kidneys is eliminated and wastes are filtered in urinary tracts. The urinary tract has an upper and lower part. This filter tube of human system often gets affected by bacterial, fungal and viral infections. However, the bacterial infection is predominant than the other two microbes [2]. UTI infection exhibits a variety of symptoms including mild burning micturition, bacteremia, sepsis and even death [3]. It is reported that UTI is affecting both genders but women in the age group 15-44 are more prone to this infection [4]. UTI infection is global and in U.S more than 150 million cases are reported every year and the economic burden is more than 6 billion [5]. About $40 \%$ women and 12\% of men suffers with UTI infection at least one time in their lifetime. But recurrent infection is also possible [1] of the different etiological agents the UTI causing bacteria may invade due to pregnancy, sexual intercourse, and family history [6]. The infecting bacteria enter the otherwise sterile urine and begin to grow. It usually develops at the opening of urethra and then spreads to the urinary tract. It is reported that the bacteria Esceherichia coli is the causative agent [7].

In women sexual activity is the major cause up to $90 \%$ of bladder infection. This is common in the initial period of marriage and so it is called "honeymoon cystitis". Further improper wiping suppressed immune system, Urinary catheter diabetes, unhygienic public toilets, birth control devices and family history may be other reasons (WWW. kindney .org/store). About $80-90$ percent of UTI is caused by a single type of bacteria [7].
Of the different types of urinary tract infection, cystitis (lower urinary tract infection) and pyelonephritis (upper urinary tract infection) are the major problems. For lower urinary tract infection, the common symptoms include inflammation and irritation in the lining of urethra and bladder, burning sensation or pain while urinating. More frequent urination and often with only a small amount of urine, sensation of having to urinate urgently, cloudy, bad smelling, or bloody urine, lower abdominal pain and mild fever. For upper urinary tract infections, the frequent symptoms include, high fever, nausea and vomiting, shaking chills, pain in back or one side of waist. In the children fever, vomiting, loss of bladder control sleeping mode is common symptoms. In the elderly fatigue is common due to UTI. Because of all these health issues, an attempt has been made to evaluate the prevalence of UTI among the population in Kanyakumari district of Tamil Nadu where women education is high. Further medical awareness is also high in this district.

\section{Material and methods}

\section{Sampling}

For the study 1824 cases with suspected urinary tract and related problems referred by medical practitioners to Vivek Clinical

${ }^{*}$ Correspondence to: Singh RAJA, Department of Biotechnology, Prathyusha Engineering College, Chennai, India, Tel: 9443451076; E-mail: ajargnr@gmail.com

Key words: UTI, bacteria, diabetes, infection, Kanyakumari

Received: September 02, 2019; Accepted: September 20, 2019; Published: September 23, 2019 
Laboratory, Nagercoil during January 2017 to June 2017 were screened for further analysis. Among the screened cases, 1138 were women and 686 were men. A clinical analysis of their urine, urino-genital system and Kidney function tests were carried out as per standard protocol. The urine culture confirming urinary tract infection positive cases were taken as infected population for further analysis. The case history and socio-economic status, age group and other demographic factors of the positive cases were recorded. Among the tested cases for kidney functioning, urinary problems, urinogenital problem or other urinary tract infection suspected cases, the positive cases were isolated and further study was conducted using their urine culture, biochemical testing of urine, and abdominal scanning.

\section{Urine examination}

The urine of suspected cases was tested for urea, uric acid, albumin, creatine, turbidity, $\mathrm{pH}$, color and odour, and microbiological components. The urine culture was made for all the samples and the infection positive cases were separated. The bacteria and fungi in the urine culture was isolated and kept in nutrient slants till they are subjected to antibiotic sensitivity assay.

\section{Collection of urine specimen from people}

Mid-stream urine was collected in a sterile dry wide necked and leak proof container. Then the containers were labeled with the date, the name, time and serial number of the patient. The collected urine specimens were transported with the temperature of $4^{\circ} \mathrm{C}$ with coolant pack to the laboratory.

\section{Epidemiological and hematological analysis}

The physiological parameters like pulse rate and blood pressure of the study group population were recorded. Hemoglobulin content of study group population was also measured by Sahli (Acid-haematin) method. The presence of sugar in urine specimen were analyzed by strip method and recorded.

\section{Physical examination of the urine specimen}

The physical parameters of collected urine specimens such as volume, $\mathrm{pH}$, color, appearance was analyzed and recoded.

\section{Microscopical examination of urine specimens}

To examine the urine specimens, microscopically wet preparation was made by centrifuging the sample at 500-1000 g for 5 minutes then a drop of sediment was transferred to a slide and covered with glass and finally it was examined under 10x and 40x objective. The crystals, casts and bacterial cells, parasites were recorded.

\section{Microbiological analysis of urine specimens}

The uropathogens were identified by swabbing the urine specimens on various selective and differential media such as Hi-chrome UTI agar, Salmonella shigella agar (SS agar), Thiosulphate citrate bile salt sucrose (TCBS) agar, BIGGY agar (Nickerson medium) and Potato Dextrose Agar (PDA) based on their color morphology after the incubation period.

\section{Results and discussion}

The results of urine examination and microbial culture positive cases and the sensitivity of isolates to drug were statistically analyzed. This analysis will provide the information about the prevalence of UTI in this area.

\section{Socio demographic study}

In the present study to find out the prevalence of UTI infection in male and female population of Kanyakumari district of Tamil Nadu, India, a total of 1824 cases were screened. Among them 1029 were women and 795 were men. The sample represented all age groups. Among the screened cases the urine culture test confirmed the positive cases of infections. The culture positive cases include 391 females and 296 males. Among the suspected cases 638 women and 499 men although showed symptoms for UTI, the urine culture results showed no positive infection. These cases may be in the initial stage or they might have reported for clinical examination after taking selfmedication with antibiotics from local medical shops (Table 1).

\section{Sex and age structure of culture positive cases}

The results show that among 1824 suspected cases, 9.93\% were male child in the age group 0-10 years and 9.56 percent were in the age groups 10-20 years. Among the screened cases (1029) 9.52 percent were in the age group $0-10$ years, 6.41 percent in $11-20$ years age group and 7.59 percent in 71-80 years age group (Table 2).

Among the screened cases the UTI suspicion was high (18.36\%) in males in the age group 61-70 years and females in the age group 21-30 years (22.54\%) and 14.29 percent in $31-40$ years age group. As the women in the age group 21-30 years are mostly married and 31-40 are in late married group, the UTI infection is suspected more in them when compared to other age groups. The males in the age group 61-70 years were more vulnerable to UTI suspicion than other age groups.

Among the UTI patients analyzed 391females and 296 males were showed culture positive (Table 3 ). Among the females, the culture positive cases were in the age group 0-100 years. Among the total female culture positive cases, $9.47 \%$ were in $0-10$ years, $11.77 \%$ in 11 20 years, $17.13 \%$ in $21-30$ years, $9.71 \%$ in $31-40$ years, $11.50 \%$ in $41-50$ years, $16.88 \%$ in $51-60$ years, $11.26 \%$.

Of the total positive cases, children account to (0-10 years) $9.47 \%$ in females and $9.46 \%$ in males. Vasudevan [1] reported that the UTI occurrence among children is global and stressed the need for imperative attention. Afsharpaiman reported community acquired UTI in children and the isolated pathogens were reported to be drug resistant. Al-Mardeni reported the problems of pediatric urinary tract infection and the prevalence of drug resistant uropathogens had increased the rate of mortality and morbidity. In the Kingdom of Saudi Arabia, geographical location, and socio-economic status were reported to influence the drug resistant pattern in pediatric UTI. Regular use of antibiotics in children for various ailments was reported to induce drug resistance in uropathogens like E.coli and Enterobacter species [1]. Pulipati et al. [8] reports that the UTI prevalence in female child in the age group 0-15 was because of anatomic or abnormalities in urologic functions, congenital defects, and vesico-uteral reflux in females. In male child along with these reasons, uncircumcised penis was added as another reason. In the personal observation and enquiry with parents and children, unhygienic napkins, poor housing conditions, poor toilet cleanliness, children playing with infected water and mother's hygiene are found to be major reasons for pediatric UTI. Hence poor personal hygiene, lifestyle malnutrition and environmental conditions are a matter of great concern in the prevention of UTI in children.

In the uropathogen culture positive females, 17.13 percent of infection was found in the age group 21-30 years and 9.71\% in 31-40 years. In the study area females are getting married mostly in between 21-33 years. Hence the "honeymoon cystitis" (UTI infection) is highly 
Table 1. Socio-demographic characteristics of UTI cases screened in Kanyakumari district of Tamil Nadu, India.

\begin{tabular}{|c|c|c|c|c|c|}
\hline \multirow[t]{2}{*}{ Characters } & \multirow[t]{2}{*}{ Parameters } & \multicolumn{2}{|c|}{$\begin{array}{l}\text { Total Number of suspected cases } \\
\text { (1824) }\end{array}$} & \multicolumn{2}{|c|}{ Positive cases } \\
\hline & & Women & Men & Women & Men \\
\hline \multirow{3}{*}{ Literacy } & Illiterate & 1029 & 795 & 391 & 296 \\
\hline & School finished & 416 & 314 & 121 & 86 \\
\hline & Graduates & 509 & 386 & 122 & 86 \\
\hline \multirow{3}{*}{ Income } & Lowincome (above Rs.5000/month) & 314 & 326 & 101 & 120 \\
\hline & Middle income (Rs 6000-20000) & 615 & 267 & 197 & 90 \\
\hline & High income (above Rs.20000) & 100 & 202 & 93 & 86 \\
\hline
\end{tabular}

Table 2. UTI suspected cases screened during the sampling period.

\begin{tabular}{|c|c|c|c|}
\hline Age & $\begin{array}{c}\text { Total number of } \\
\text { Male patients }\end{array}$ & $\begin{array}{c}\text { Total number of } \\
\text { Female patients }\end{array}$ & Total \\
\hline $0-10$ year & $79(9.93 \%)$ & $98(9.52 \%)$ & 177 \\
\hline $10-20$ year & $76(9.56 \%)$ & $66(6.41 \%)$ & 142 \\
\hline $21-30$ year & $86(10.81 \%)$ & $232(22.54 \%)$ & 318 \\
\hline $31-40$ year & $94(11.82 \%)$ & $147(14.29 \%)$ & 241 \\
\hline $41-50$ year & $107(13.45 \%)$ & $129(12.53 \%)$ & 236 \\
\hline $51-60$ year & $96(12.07 \%)$ & $129(12.53 \%)$ & 225 \\
\hline $61-70$ year & $146(18.36 \%)$ & $121(11.96 \%)$ & 267 \\
\hline $71-80$ year & $78(9.81 \%)$ & $78(7.59 \%)$ & 156 \\
\hline $81-90$ year & $33(4.16 \%)$ & $28(2.72 \%)$ & 61 \\
\hline $91-100$ year & - & $0(0.09 \%)$ & 1 \\
\hline Total & 795 & 1029 & 1824 \\
\hline
\end{tabular}

prevalent in this group. A personal enquiry with the culture positive cases revealed that $33.4 \%$ of them have got this infection for the second and third time. Of the reported positive cases 41.2 percent are pregnant. Vasudevan [1] in his review states that about $56 \%$ of pregnant women develop UTI and the incidence is high up to $50 \%$ during second trimester among the pregnant women.

There are many reports about the proximity of pregnant women getting UTI. About $14-10 \%$ of pregnant women were reported to be affected by UTI [8-10]. Pregnant women diagnosed with asymptomatic bacteria are more prone to develop pyelonephritis. As pregnancy is associated with many anatomical and physiological changes of the urinary tract, nephritis is common. The development of pyelonephritis is more seen in second half of pregnancy because at this stage the uterus gets widened and compresses the adjacent urinary bladder. So, a complete elimination of urine is reduced. The retention or residual urine in the bladder facilitates the microbial infection leading to vomiting, flank pain, and fever. Hormonal changes during pregnancy are also reported to influence UTI infection.

Alemu et al. [8] reported that in Ethiopia the prevalence of UTI among pregnant was in the range $2.5-15 \%$. As pregnancy advances, the uterus enlarges and presses the urinary bladder and that influences the urinary tract tissues to get infection (Mittal and Wing, 2005). Factors like the history of previous infection, diabetes and physiological aberrations of the urinary tract also influence the infection.

Muthulakshmi et al. [3] study on UTI in females showed that women in the reproductive age 14-44 years are the vulnerable group for UTI infection and $25-30 \%$ women between 20-40years of age are much affected [11]. Kant et al. [4] also reported UTI in 33.3\% of pregnant women. Bhartisingh et al. [12] reported episodes of UTI in $48 \%$ of women in Ravindrapuri near Varanasi. The short urethra, behavioral factors like delay in micturition, sexual activity and the use of contraceptives which promote colonization of the periurethral area with coliform bacteria [13]. Smaill et al. [14] stated that pregnant women with UTI normally becomes hypertensive, develops anemia, renal problems, prematurity and babies with low birth weight. Researchers have validated the significance of physiological changes as one of the vital factors for the occurrence of UTI during pregnancy. Factors like hormonal, mechanical and physiological changes during pregnancy ads up to the vital changes in the urinary tract [15].

In addition to the women in reproductive age group, the UTI infection in women with menopausal age is also high (Table 2). About $16.88 \%$ of the UTI culture positive women (391 cases) are in the age group 51-60. The incidence of UTI in between reproductive age (2130 years) and premenopausal, menopausal and post-menopausal stage women also endured high incidence of UTI. In the women in the age group 51-60 years, the incidence of UTI is relatively high. Of the tested cases (68.3 percent are diabetic and diabetic women are having more affinity towards UTI uropahtogens. Harjustsalo et al. [16] demonstrated that there is a link between diabetes and UTI in women. Women with diabetes are much prone to uropathogen invasions by fungi and bacteria because the distal region of the urinogenital tract and its opening may have glucose enriched urine which could help the micro flora to flourish. Further diabetic women have frequent irritation, sensation in the vaginal region reported the association between diabetes and UTI. The bacteria may be in the urine without expressing any symptoms (asymptomatic). In these cases of asymptomatic bacteriuria the bacterial count is less than $\geq 10^{5} \mathrm{CFU} /$ $\mathrm{ml}$ in the midstream urine. The asymptomatic bacteriuria in diabetic women is reported to impair kidney functions [17]. Murugan [18] had reported that in the Kanyamumari district the diabetes prevalence is community dependent and overall diabetic cases in this district is 15.80 males and 15.22 females and among the people in the age group $55-89$ $33.09 \%$ are diabetic.

Patients diagnosed with diabetes often encounter the dire consequences of UTI which includes emphysematous cystitis and pyelonephritis, fungal infections. Candida is the common fungal species known to confer the disease. In the present study area women diabetic patients are high in number. In the present study women in the age group 61-100 years too got UTI. In women above 61-70 years of age $7.41 \%$ are reported with symptomatic UTI. UTI has not spared a woman in the age group 91-100 years. The high prevalence of UTI in women above 60 years of age is mostly because of diabetes as diabetic type II positive cases are $79.6 \%$ among them. Pulipati et al. [8] reports that the incidence of UTI infection in elderly women is due to many factors including bladder prolapse, previous infection, estrogen deficiency and loss of vaginal lactobacilli.

In males the prevalence of UTI in different age groups are given below viz; $0-20$ years $9.56 \%, 21-30$ years $10.8 \%$, $31-40$ years $11.82 \%$, 41 50 years $13.45 \%$, $51-60$ years $12.07 \%, 61-70$ years $18.36 \%, 71-80$ years 
9.81\% and there is no representation in 91-100 years. But in female there was a case with UTI in this age group (91-100). This shows that the longevity of women is more than men in this district.

Pediatric urinary tract infection was observed in the present study. The proportion of pediatric UTI cases represents $9.93 \%$ in the suspected cases and among them $9.46 \%$ were culture positive. Singh-Grewal et al. [19] reported that circumcision reduces the risk of UTI in normal boys. Field states that about 10 percent of low-birth weight infants are affected by UTI. The reasons for childhood UTI include, vesicoureleral reflux with pathogenesis of renal scarring, reflux nephropathy, pylenonephritis and voiding disorders [20] (Figure 1 and Table 4).

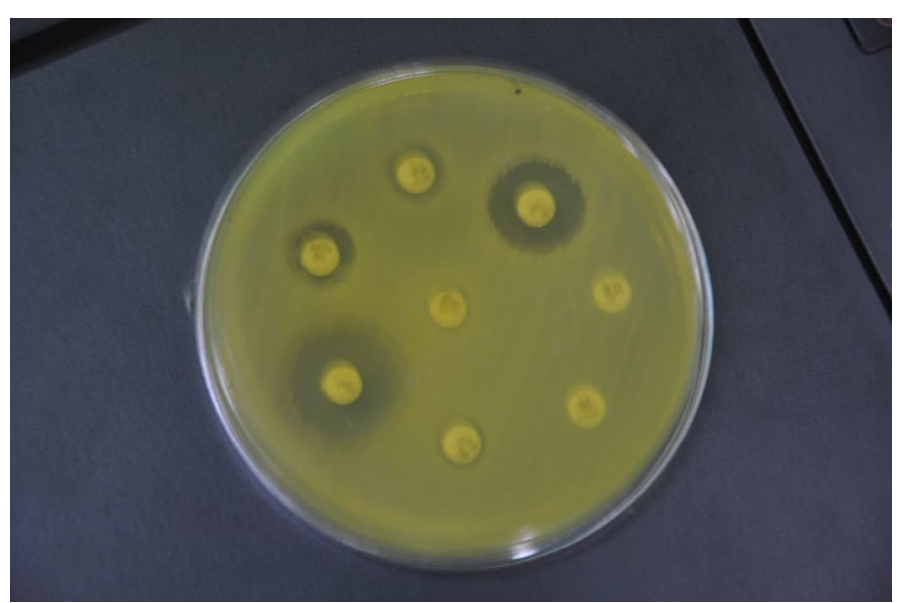

Figure 1. E.coli showing resistance to drugs but sensitive to AgNPs

Table 3. Age and sex wise distribution of urine culture positive patients in Kanyakumari District of south India.

\begin{tabular}{|c|c|c|c|}
\hline Age & \multicolumn{2}{|c|}{ Urine culture positive cases (\%) } & Total Number \\
\hline & Males & Females & \\
\hline $0-10$ year & $28(9.46 \%)$ & $37(9.47 \%)$ & 65 \\
\hline $10-20$ year & $38(12.83 \%)$ & $46(11.77 \%)$ & 84 \\
\hline $2-30$ year & $18(6.09 \%)$ & $67(17.13 \%)$ & 85 \\
\hline $31-40$ year & $31(10.48 \%)$ & $38(9.71 \%)$ & 69 \\
\hline $41-50$ year & $31(10.48 \%)$ & $45(11.50 \%)$ & 76 \\
\hline $51-60$ year & $30(10.13 \%)$ & $66(16.88 \%)$ & 96 \\
\hline $61-70$ year & $52(17.57 \%)$ & $44(11.26 \%)$ & 96 \\
\hline $71-80$ year & $43(14.52 \%)$ & $29(7.41 \%)$ & 72 \\
\hline $81-90$ year & $25(8.44 \%)$ & $18(4.60 \%)$ & 43 \\
\hline $91-100$ year & - & $1(0.26 \%)$ & 1 \\
\hline Total & 795 & 391 & 1186 \\
\hline
\end{tabular}

Table 4. Microbial consortium isolated from urinary tract infected cases in Kanyakumari District of south India

\begin{tabular}{|c|l|}
\hline S.No & Microbes in urine culture \\
\hline 1 & Escherichia coli \\
\hline 2 & Klebsiella pneumonia \\
\hline 3 & Staphylococcus saprophyticus \\
\hline 4 & Pseudomonas aeruginosa \\
\hline 5 & Morganella morganii \\
\hline 6 & Streptococcus sps \\
\hline 7 & Staphylococcus aureus \\
\hline 8 & Enterococcus sp \\
\hline 9 & Proteus vulgaris \\
\hline 10 & Chromobacterium violaceum \\
\hline 11 & Serratia sps \\
\hline 12 & Fungus- Candida albicans \\
\hline
\end{tabular}

\section{Conclusion}

In the present study elderly men are affected by UTI to an extent of 40.53 percent (age group 61-90years). Faryabi et al. [21] reported UTI as one of the most prevailing causes of infectious diseases among geriatric population in both genders and a similar report was made Prakasam et al. [22]. But the present study showed an opposite condition and males are less prone to UTI when compared with females.

The high incidence of UTI in male senior citizens or people above 60 years of age is closely linked to diabetes and prostrate conditions. In the male sample screened for UTI infection with age above 61 years showed that the elderly people with diabetics are much affected by UTI [23].

In the present study the incidence UTI decreased during middle age but rises in adults above 60 years. In the present study also, it is observed. It is reported that in both men and women UTI incidence increases over the age of 85 years. Further in the elderly people asymptomatic bacteriuria (ASB) is often confused with UTI.

\section{UTI and gender comparison}

In the study area the patients with the complaint of "Suspected" UTI are more seen in females (1029) than males (795). But culture tests revealed a different statistic. The percentage of culture positive males is $37.23 \%$ and female patients are $37.99 \%$. The results indicate that the prevalence of UTI in males and females are more or less equal.

In the age group 0-10 years out of 79 suspected cases, 28 (35.44\%) are culture positive in males but in females it was 37.76 percent. In the age group 11-20 out of 76 suspected UTI males $50 \%$ are culture positive but in female's 69.70 percent are culture positive. In the age group 21-30, out of 86 suspected males 18 (20.9\%) are culture positive whereas in female's 28.88 percent are culture positive in 232 suspected cases. In the females the patients with asymptomatic nature is 232 . In this age group culture positive is only 67 females. The results show that more number of females in this age group 21-30 is complaining of urinary tract problem. This shows that the reproductive or initial stage of married women is more in this group. Although the women in this group are suspected to be infected with UTI the symptomatic culture positive cases are less. In males in the age group 51-70 years 242 UTI suspected cases were tested. Among them, 82 persons ( 33.88 percent) are culture positive. But in women in this age group out of the 250 cases tested $44.0 \%$ are culture positive.

\section{Microbial consortium isolated from UTI Samples}

The samples taken from urinary tract infected with microbes and urine showed the presence of different types of bacterial and fungal pathogens. The bacterial isolates included Escherichia coli, Klebsiella pneumoniae, Staphyllococcus saprophyticus, Margonella margonii, Streptococcus sp, Staphyllococcus aureus, Enterococcus sp, Proteus vulgaris, Chromobacterius violaceum, Serratia $s p p$ and the fungi Candida sp.

\section{References}

1. Vasudevan R (2014) Urinary tract infection:an overview of the infection and the associated risks factors. J Microbiology Exp 1: 1-5.

2. Demilie T, Beyene G, Melaku S, Tsegaye W (2012) Urinary bacterial profile and antibiotic susceptibility pattern among pregnant women in north west Ethiopia. Ethiop $J$ Health Sci 22: 121-128. [Crossref]

3. Muthulakshmi M, Gopalkrishnan S (2017) Study on urinary tract infection among females of reproductive age group in a rural area of Kancheepruam district, Tamil Nadu. Int J Commu Med Public Health 4: 3915-3921. 
4. Kant S, Misra P, Gupta S, Goswami G, Krishnan K, et al. (2018) The ballabgarh health and demographic surveillance system (CRHSP-AIMS). Int J Epidemiol 42: 758-68.

5. Foxman B (2010) The epidemiology of urinary tract infection:Economic considerations. Nat Rev Urol 7: 653-60.

6. Fatima N, Ishrat S (2006) Frequency and risk factors of asymptomatic bacteriuria during pregnancy. J Coll Physicians Surg Pak 16: 273-275. [Crossref]

7. Li X, Chen Y, Gao W (2017) A six year study of complicated urinary tract infections in southern china:prevalence, antibiotic resitance, clinical and economic outcomes. Ther Cli Risk Mang 13: 1479-1487. [Crossref]

8. Pulipati S, Babu PS, Narasu L, Anusha NM (2017) An overview on urinary tract infections and effective natural remedies. J Medici Plants Studies 5: 50-56.

9. Alemu A, Moges F, Shiferaw Y, Tafess K, Kassu A, et al. (2012) Bacterial profile and drug susceptibility pattern of urinary tract in pregnant women at University of Gondar Teaching Hospital, Northwest Ethipia. BMC Res Notes 5: 197. [Crossref]

10. Moyo SJ, Aboud S, Kasubi M, Maselle SY (2010) Bacterial isolates and drug susceptibility patterns of urinary tract infection among pregnant women at Muhimbili National Hospital in Tanzania. Tanzan J Health Res 12: 236-240. [Crossref]

11. Wilma JP (2002) Medical Surgical Nursing. ( $7^{\text {th }}$ edn). B.I.Publications, New Delhi, pp: 637-640.

12. Singh B, Katiyar D, Tilak R, Srivastava RK, Chauhan RS (2018) Prevalence of UTI causing microorganisation and determination of susceptibility to antibiotic among slum women of Varanasi, India. Int J Curr Microbiol Applied Sci 7: 3483-3497.

13. Litza JA, Brill JR (2010) Urinary tract infections. Primary Health care 37: 491-507.
14. Smaill F, Vazquez JC (2007) Antibiotics for asymptomatic bacteriuria in pregnancy. Cochrane Database Syst Rev 2: CD000490.

15. Olson PD, Hruska KA, Hunstad DA (2016) Androgen enhance male urinary tract infection severity in a new model. J Am Soc Nephrol 27: 1625-1634. [Crossref]

16. Harjutsalo V, Sjoberg L, Tuomilehto J (2008) Time trends in the incidence of type I diabetes in finnish children. A cohort study. Lancet 371: 1777-1782. [Crossref]

17. Karunajeewa H, McGechie D, Stuccio G, Stingemore N, Davis WA, et al. (2005) Asymptomatic bacteriuria as a predictor of subsequent hospitalization with urinary tract infection in diabetic adults: The Fremantle Diabetes Study. Diagbetologia 48: 1288-1291. [Crossref]

18. Murugan A (2014) Type 2 diabetes mellitus is it habitat specific. IOSR-JPBS 9: 46-51

19. Singh-Grewal D, Macdessi J, Craig J (2005) Circumcision for the prevention of urinary tract infection in boys:a systematic review of randomized trials and observational studies. Arch Dis Child 90: 853-858.

20. Sujatha R, Nawani M (2014) Prevalence of asymptomatic bacteriuria and it antibacterial succeptibility pattern. J Clin Diag Res 8: DCO1-DCO3. [Crossref]

21. Faryabi R, Mathew J, Palaye M, Nair S, Shivashankar S, et al. (2014) Anbiotic utilization in patients with complicated urinary tract infection in the medicine wards of a South Indian tertiary care teaching hospital. RJPBCS 5: 87-94.

22. Prakasam AKC, Dileesh KKG, Vijayan M (2012) A cross sectional study on distribution of urinary tract infection and their antibiotic utilization pattern in Kerala. Int J Pharm Tech Res 4: 1310-1316.

23. Kakde P, Redkar NR, Yelale A (2018) Urinary Tract infection in Elderly:clinical profile and outcome. J Associ Physicians: 66.

Copyright: (C2019 Christy VR. This is an open-access article distributed under the terms of the Creative Commons Attribution License, which permits unrestricted use, distribution, and reproduction in any medium, provided the original author and source are credited. 